\title{
Comprehensive Prediction of Thermosyphon Characteristics in Reactor Passive Cooling System Simulation Loop FASSIP-01
}

\author{
H. Tjahjono* \\ Center for Nuclear Reactor Technology and Safety, National Nuclear Energy Agency, \\ Puspiptek Area Serpong, Tangerang Selatan 15310, Indonesia
}

\section{ARTICLE INFO}

\section{Article history:}

Received 31 October 2016

Received in revised form 22 June 2017

Accepted 17 July 2017

\section{Keywords:}

Thermosyphon

Passive system

Nuclear reactor

FASSIP-01 model

MATLAB

\begin{abstract}
A B S T R A C T
Passive cooling mechanism for a nuclear reactor has been proven to be very important since the Fukushima Daiichi Reactor accident that was caused by active cooling system malfunction due to total loss of electrical power source. In the Center for Nuclear Reactor Technology and Safety of BATAN, the cooling mechanism was studied by using a natural circulation test loop named FASSIP-01 that applied thermosyphon mechanism of water inside pipes of 1 " diameter. This study aimed to analytically predict the thermal characteristics of the loop including its response time towards steady condition using the MATLAB calculation program. This prediction derived the influence of several parameters such as the heat transfer coefficient of the cooler side (h-cooler), the heater power, the elevation difference between the heater and cooler $(\Delta Z)$, and the effects of the insulation thickness of pipe (IT) on the flowrate, temperature, and the heat power distribution across all components in the loop. The result showed that by avoiding boiling condition, for transferring the heater power of $1000 \mathrm{~W}$ and $2000 \mathrm{~W}$, the needed h-cooler exceeds 200 and $400 \mathrm{~W} \mathrm{~m}^{-2}{ }^{\circ} \mathrm{C}^{-1}$, respectively. For a h-cooler of $200 \mathrm{~W} \mathrm{~m}^{-2}{ }^{\circ} \mathrm{C}^{-1}$, the circulation flow rate increased from 0.04 to $0.06 \mathrm{~kg} / \mathrm{s}^{-1}$ for heater power increase from $1000 \mathrm{~W}$ to $2000 \mathrm{~W}$. Those flow rates were decreased to 0.037 and $0.052 \mathrm{~kg} \mathrm{~s}^{-1}$ by increasing h-cooler to $1000 \mathrm{~W} \mathrm{~m}^{-2}{ }^{\circ} \mathrm{C}^{-1}$. The results were in agreement with other studies on rectangular loops in the literature. The time needed to reach $95 \%$ towards steady state was predicted to be more than 13 hours. Reduction of this time to less than five hours was possible by reducing the heater tank volume from $100 \mathrm{~L}$ to $30 \mathrm{~L}$ or by modifying the starting heater input power.
\end{abstract}

(C) 2017 Atom Indonesia. All rights reserved

\section{INTRODUCTION}

Natural circulation becomes an important mechanism in the heat evacuation process in a new generation of nuclear reactors that emphasize inherent safety without depending on external power sources. The accident at the Fukushima Daiichi reactor has proven how important the use of passive cooling in nuclear reactors is, especially in the event of station blackout accidents [1]. The accident was classified as an International Nuclear Events Scale (INES) level 7 accident [2]. Research activities related to natural cooling that are mainly associated

*Corresponding author.

E-mail address: hendro@batan.go.id

DOI: https://doi.org/10.17146/aij.2017.777 with thermosyphon mechanism has been increasing since the accident, eventhough the technology has already been used in solar water heating [3]. Reactor designs using passive cooling system have also been developed and studied, especially on modular reactors, such as the HTR-MODUL that has a cavity cooler system to absorb the residual heat in the case of loss of flow accident [4], a small pebble-bed reactor which passively transfers the decay heat through cavity cooler to surrounding soil [5], the AP1000 reactor that uses a passive residual heat removal system to transfer the core residual heat to the environment [6], the CPR1000 with its new design of emergency passive residual heat removal system [7], the AREVA-HTR which transfers the residual heat by radiation into the reactor cavity 
where it is removed by Reactor Cavity Cooling System (RCCS) using thermosyphon mechanism [8], the HTR-PM with its natural circulating of residual heat removal system [9], and the SMART with passive residual heat removal systems that remove the core decay heat through natural circulation at any design basis events [10]. In those reactors, passive cooling mechanism can be used either for normal operating conditions on small power reactors or on the accident conditions in the large power reactors such as the AP1000.

Natural circulation cooling mechanism in a closed cycle is known as the thermosyphon. In this mechanism, the heat is transferred from the heat source to the heat sink with different elevation. The elevation of the heat sink should be higher or equal to the heat source. The fluid moving in this mechanism can be a gas or a liquid, but if the gas is used, its effectiveness is very low due to the it slow conductivity compared to that of a liquid. Therefore, high-temperature reactors (HTRs) that use helium gas as the working fluid, in normal conditions, use forced circulation with blower, whereas the application of thermosyphon is used only to evacuate the decay heat when an accident occurs and leads to the loss of active flow [11]. The working fluid used in thermosyphon loop is water that serves to evacuate the heat passively from the heater side to the cooler side. In the AP1000 reactor, the use of thermosyphon mechanism is applied when the reactor is shutdown and there is no forced flow through the pump. Heat transfer takes place from the heat source, in the reactor core, to the heat sink, in the passive residual heat removal system (PRHRS) which is then transferred to be absorbed by water in the in-containment refueling water storage tank (IRWST). Mayur Krishnani and Dipankar N. Basu studied the validity of Boussinesq approximation in transient simulation of singlephase natural circulation 1" pipe loops using 3-D computational model of a rectangular loop. The result shows that with Boussinesq approximation, the mass flow rate changes from $0.034 \mathrm{~kg} \mathrm{~s}^{-1}$ to $0.050 \mathrm{~kg} \mathrm{~s}^{-1}$ with the power changes from $1000 \mathrm{~W}$ to $2000 \mathrm{~W}$ [12]. Investigations on single-phase natural circulation loop dynamics are also done by Kumar Naveen et al. through a rectangular adiabatic loop with horizontal heater and horizontal cooler using 1" pipe diameter $[13,14]$. The investigation gives the variation of flow rate from $0.010 \mathrm{~kg} \mathrm{~s}^{-1}$ to $0.030 \mathrm{~kg} \mathrm{~s}^{-1}$ for the variation of heater power from $100 \mathrm{~W}$ to $700 \mathrm{~W}$.

Considering the importance of this mechanism in ensuring the safety of the reactor, the understanding of the phenomenon in more detail through a characterization of thermosyphon mechanism was needed. Using the 2015 budget, an experimental model of thermosyphon named FASSIP-01 was developed in order to characterize in more detail the parameters associated with the phenomenon. In particular, as part of the development of the experimental model, this study aimed to predict the thermal characteristics of the loop including its response time towards the steady condition. The thermal characteristics to be predicted consisted of the temperature, flow rate, and heat power as a function of elevation difference between heat source and heat sink, the thickness of loop insulation, and the heat transfer coefficient of heat sink (h-cooler). With the predicted results, it was expected to choose more precise experimental conditions, such as how much the effectiveness of the coolant should be conditioned, how thick the pipe insulation should be used, and how much power the maximum heating is provided.

The method used in this prediction began by developing a calculation program based on MATLAB 7. The program applied an iterative algorithm in order to accommodate changes in the physical properties of working fluids and structures against temperature. Some parts of the program were in coincidence with the program made for investigating the performance of passive containment cooling system in AP1000 reactor against the change of air condition [15] and the program for investigating the AP1000 containment pressure and temperature transient under station blackout accident with different pressure set points [16]. With the created program, the effect of the changes of h-cooler on the temperature and flow rate in the loop for different heating powers were predicted. The program also predicted the effects of the pipe insulation thickness on temperature and flow rate for different heater power and cooling effectiveness.

\section{THEORY}

\section{Thermosyphon mechanism in FASSIP-01}

The FASSIP-01 facility is a natural circulation loop using thermosyphon principle that aims to study the characteristics of passive cooling in a nuclear reactor. It was built to study the characteristics of passive cooling in PRHRS. The description of FASSIP-01 loop refers to the rectangular loop shown in Fig. 1 with the height $H=7 \mathrm{~m}$, width $W=3.5 \mathrm{~m}$, and $\Delta Z=6 \mathrm{~m}$, and with pipe diameter of 1 ". The volume of water inside the heater tank is arround $200 \mathrm{~L}$, and it is heated using an electrical heater with variable electric 
power. The water in the heater is separated from the water circulating in the loop. As a part of the heat transfer mechanism by natural convection, the flow mechanism in the thermosyphon resulted from the differences in fluid density as a result of the fluid thermal expansion with the temperature. For the mechanism to continue, it needs two different sources, namely a source of hot temperature condition (heat source) and a source of cold temperature condition (heat sink). A heat source can be either a source with controlable heat power or one with controlable temperature. The heat sink is generally in the form of heat exchanger with a cold fluid on the secondary side. In addition to the temperature difference, another driving force of the flow in natural convection is the height the fluid column of different temperatures or densities. This column height is determined by the elevation difference $(\Delta Z)$ between the heat source and heat sink. If the heat sink is under the heat source, the thermal stratification of temperature will happen so it can not produce a force to flow the fluid.

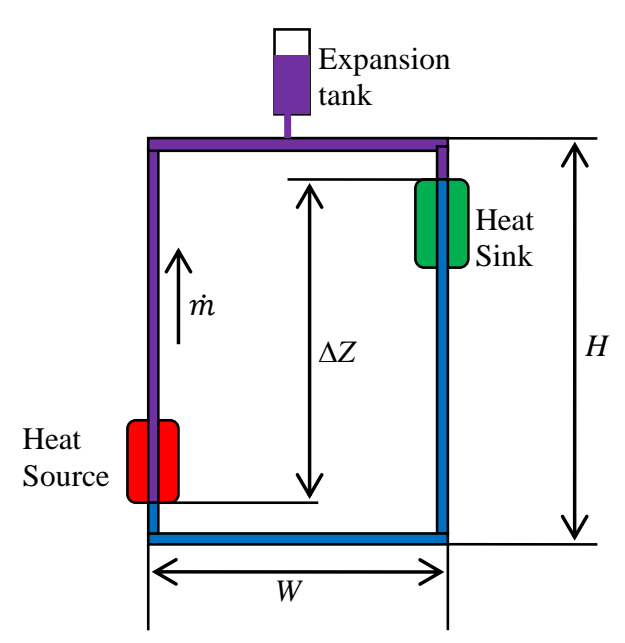

Fig. 1. The scheme of thermosyphon loop.

The design concept is also applied to the cooler (heat sink) that also has a volume of about 200 Land contains water that is separated of the water inside the rectangular loop. The cooler uses a cooling system that can reach water temperatures below $10{ }^{\circ} \mathrm{C}$. Water pressure in the loop is kept at $1 \mathrm{~atm}$ using an expansion tank above the loop.

Table 1 shows the effect of temperature on the physical properties of water that have significant effect in thermal hydraulic parameters. The temperature range used in the table is adjusted to the temperature range between the minimum and maximum possible in $1 \mathrm{~atm}$ of pressure.

It can be seen in the table that in that temperature range, the effect of temperature on thermal diffusivity $\alpha$ is relatively small. However, the effect of temperature is significant for the kinematic viscosity $v$, the coefficient of thermal expansion $\beta$, and Prandtl number $P r$. The last column in the table is used to look at the effect of temperature on the physical properties of factor $K=g \beta /(v \alpha)$ of the dimensionless Rayleigh number $\left(R a=K \Delta T \cdot H^{3}\right)$ which characterizes the flow and heat transfer of natural convection. The value of $K$ changes by a factor of approximately 30 with increasing temperature from $10^{\circ} \mathrm{C}$ to $100^{\circ} \mathrm{C}$.

Table 1. Change of water physical properties with temperature

\begin{tabular}{cccccc}
\hline $\begin{array}{c}\text { Temperature } \\
\left({ }^{\circ} \mathrm{C}\right)\end{array}$ & $\begin{array}{c}\alpha \\
\left(10^{-7} \mathrm{~m}^{2} \mathrm{~s}^{-1}\right)\end{array}$ & $\begin{array}{c}v \\
\left(10^{-7} \mathrm{~m}^{2} \mathrm{~s}^{-1}\right)\end{array}$ & $\begin{array}{c}\beta \\
\left(10^{-4} \mathrm{~K}^{-1}\right)\end{array}$ & $P r$ & $\begin{array}{c}R a \text { factor } \\
\left(10^{-9} g \beta /(v \alpha)\right)\end{array}$ \\
\hline 10 & 1.40 & 13.11 & 0.89 & 9.39 & 0.49 \\
20 & 1.44 & 10.09 & 2.08 & 6.99 & 1.42 \\
30 & 1.49 & 8.07 & 3.04 & 5.41 & 2.53 \\
40 & 1.53 & 6.61 & 3.86 & 4.32 & 3.82 \\
50 & 1.56 & 5.59 & 4.58 & 3.57 & 5.25 \\
60 & 1.59 & 4.79 & 5.24 & 3.01 & 6.87 \\
70 & 1.62 & 4.16 & 5.85 & 2.56 & 8.66 \\
80 & 1.65 & 3.67 & 6.42 & 2.23 & 10.61 \\
90 & 1.67 & 3.30 & 7.04 & 1.98 & 12.79 \\
100 & 1.69 & 2.95 & 7.50 & 1.75 & 15.07 \\
\hline
\end{tabular}

\section{Prediction of flow rate}

Referring to Figure 1, these two sources can maintain the continuity of the existence of two water column with different density along the elevation difference $\Delta Z$. In this model, the fluid flow is driven by an energy head that is referred to as the thermosyphon head $(T H)$. This energy is a function of the temperature difference between the hot water $T_{H}\left({ }^{\circ} \mathrm{C}\right)$ and the cold water $T_{C}\left({ }^{\circ} \mathrm{C}\right)$, the elevation difference $\Delta Z(\mathrm{~m})$ in condition of the position of heat source is lower or equal than the heat sink, and expansion coefficient $\beta\left(\mathrm{K}^{-1}\right)$, as given by (1).

$$
T H=\beta \cdot\left(T_{H}-T_{C}\right) \cdot \Delta Z
$$

The parameter $\Delta Z$ in this case is the elevation difference between the inlet side of the cold source with the inlet side of the heat source.

The energy lost due to friction or referred to as friction head and defined in equation (2).

$$
F H=f \frac{L}{D} \frac{V^{2}}{2 g}+K \frac{V^{2}}{2 g}
$$

where $f$ is the regular friction coefficient, $L$ is the pipe length (m), $D$ is the pipe diameter (m), $V$ is the average velocity $\left(\mathrm{m} \mathrm{s}^{-1}\right), g$ is the gravitational acceleration $\left(\mathrm{m} \mathrm{s}^{-2}\right), K$ is the sum of singular friction coefficient that depends on such factors as the number of bends, tees, and reducers. 
In steady state, the flow will reach a stability when the thermosyphon head is equal to the friction head. By equating equations (1) and (2), the flow velocity is obtained as given in equation (3).

$$
V=\sqrt{\frac{\beta\left(T_{H}-T_{C}\right) \Delta Z}{f \frac{L 1}{D 2 g}+\frac{K}{2 g}}}
$$

Thus, by knowing the geometry of the system and its physical properties, one can obtain the flow characteristics of velocity Vand flow rate $\dot{m}$ from equation (4):

$$
\dot{m}=\rho V \cdot A
$$

Where $A$ is cross-sectional area of flow which is equal to the pipe inside cross-sectional area $\left(\mathrm{m}^{2}\right)$ and $\rho$ is the liquid density $\left(\mathrm{kg} \mathrm{m}^{-3}\right)$. The value of the temperature difference in the loop is assumed to be equal to the value of the temperature difference at the inlet and outlet sides of the heater. Therefore:

$$
T_{H}-T_{C}=\frac{Q}{\dot{m} c_{P}}
$$

In (5), $Q$ represents the heater power (W).

By substituting (5) into(3), and then into(4), the velocity approached under steady conditions is obtained as shown in equation (6).

$$
V=\left[\frac{\beta Q \Delta Z}{\rho A c_{P}\left(f \frac{L 1}{D 2 g}+\frac{K}{2 g}\right)}\right]^{\frac{1}{3}}
$$

The assumptions made above will be close to reality if the entire pipe is adiabatic. If there is a heat loss in real terms, the average temperature difference will be reduced, and so will the energy of motion be.

\section{Loop temperature prediction}

In the heat sink, the secondary side will be conditioned by the constant input temperature, and the flow rate is relatively large compared to the flow rate in the primary side or the side of the loop thermosyphon. The primary side temperature will depend on the amount of power transferred, the temperature of the secondary side, and the total heat transfer coefficient between the primary and secondary side. Using the symbol $Q_{D}$ for the power of heat transferred to the heat sink (W), $U$ for the total heat transfer coefficient $\left(\mathrm{Wm}^{-2} \mathrm{~K}^{-1}\right)$, and $A$ for the equivalent area of heat transfer $\left(\mathrm{m}^{2}\right)$, the relationship between these parameters is given in equation (7)

$$
Q_{D}=U A \cdot L M T D
$$

Where LMTD stands for Logaritmic Mean Temperature Difference, defined in equation (8):

$$
L M T D=\frac{\left(T_{P 1}-T_{S 1}\right)-\left(T_{P 2}-T_{S 2}\right)}{\operatorname{Ln}\left[\frac{T_{P 1}-T_{S 1}}{T_{P 2}-T_{S 2}}\right]}
$$

with

$T_{P 1}=$ primary side inlet temperature $\left({ }^{\circ} \mathrm{C}\right)$

$T_{S 1}=$ secondary side outlet temperature $\left({ }^{\circ} \mathrm{C}\right)$

$T_{P 2}=$ primary side outlet temperature $\left({ }^{\circ} \mathrm{C}\right)$

$T_{S 2}=$ secondary side of the inlet temperature $\left({ }^{\circ} \mathrm{C}\right)$

The $U A$ value is the total heat transfer coefficient times the area of equivalence of heat transfer. By considering the difference between primary and secondary side, the value $U A$ is formulated in equation (9).

$$
U A=\frac{1}{\frac{1}{h_{P} A_{P}}+\frac{d}{k_{d} A_{P}}+\frac{1}{h_{S} A_{S}}}
$$

with:

$h_{P}=$ primary side heat transfer coefficient $\left(\mathrm{Wm}^{-2}{ }^{\circ} \mathrm{C}^{-1}\right)$

$A_{P}=$ area of primary side heat transfer $\left(\mathrm{m}^{2}\right)$

$h_{S}=$ secondary side heat transfer coefficient $\left(\mathrm{Wm}^{-2}{ }^{\circ} \mathrm{C}^{-1}\right)$

$A_{S}=$ area of the secondary side heat transfer $\left(\mathrm{m}^{2}\right)$

$k_{d}=$ thermal conductivity of the wall $\left(\mathrm{Wm}^{-1}{ }^{\circ} \mathrm{C}^{-1}\right)$

$d=$ wall thickness (m)

The heat transfer coefficient of the primary side of the heat sink depends on the flow rate generated by the loop thermosyphon as given by (6). In the heat sink, the flow can be considered as forced convection flow. Therefore, it can be calculated using the equations for forced convection inside the pipe with Nusselt number given in (10).

$$
N u=C R e^{m} \operatorname{Pr}^{n}
$$

Where $C, m$, and $n$ are constants, Re is Reynolds number $R e=(V D) / v, V$ is velocity, $D$ is the pipe diameter, $v$ is kinematic viscosity $\left(\mathrm{m}^{2} \mathrm{~s}^{-1}\right)$, and $P r$ is the Prandtl number. For turbulent flow with $R e>$ 3000, the equation proposed by Dittus and Boelter can be used with the value of $C=0.023$, $m=0.8$, and $n=0.3$ (for the heat sink) or $n=0.4$ (for the heat source). If the Nusselt number is known, the primary side of the heat transfer coefficient can be calculated by equation (11):

$$
h_{p}=\frac{N u \cdot k}{D}
$$

where $k$ is the thermal conductivity of water $\left(\mathrm{W} \mathrm{m}^{-1}{ }^{\circ} \mathrm{C}^{-1}\right)$. 
For a perfectly isolated or adiabatic loop, the value $T_{P 1}$ is equal to $T_{H}$ and $T_{P 2}$ is equal to $T_{C}$, while the value of $Q_{D}$ is equal to $Q$ in equation (5). Using equations (5) and (7) supported by (8) to (11), the temperature of FASSIP-01 loop can be obtained. For non-adiabatic loops, $Q_{D}<Q$ because of the heat loss in the pipeline. The heat loss can be calculated by determining the value of global heat transfer coefficient from water to air through several layers of thermal resistance, namely: convection natural by water in the inner wall, conduction in the pipe wall, conduction in the insulation, and combined natural convection and radiation into the air on insulation surface.

\section{Transient prediction towards a steady state temperature}

For scheduling the operation of the FASSIP01 loop, it is neccessary to predict the time required towards steady state condition starting from turning on the electrical heater.

In this prediction, the fluid in the loop is modeled as three separated subsystems, namely the heater (heat source), the FASSIP-01 loop, and the cooler (heat sink). Between the subsystems, there are five heat transfer surfaces, namely: the surface of electrical heater inside the heater; the contact surface between the heater and the FASSIP-01 loop; the heat loss surface area through the heater wall to the surrounding air; the heat loss surface area through the loop wall to the surrounding air; and the surface area to evacuate heat from the loop to the cooler. With the mass of water in the subsystem $m$ $(\mathrm{kg})$, specific heat $c_{P}\left(\mathrm{~J} \mathrm{~kg}^{-1}{ }^{\circ} \mathrm{C}^{-1}\right)$, input power $P$ (W), heat surface area $A\left(\mathrm{~m}^{2}\right)$, total heat transfer coefficient through the heat surface $U\left(\mathrm{~W} \mathrm{~m}^{-2}{ }^{\circ} \mathrm{C}^{-1}\right)$, average temperature of the subsystem as a function of time $T\left({ }^{\circ} \mathrm{C}\right)$, ambient temperature $T_{a}\left({ }^{\circ} \mathrm{C}\right)$, and the secondary side of cooler temperature $T_{c}\left({ }^{\circ} \mathrm{C}\right)$ that is assumed to be constant, the heat transfer model is configured in Fig. 2. Subscript 12 means the heat transfer occurs from subsystem 1 to 2 . Subscript 23 means transfer occurs from subsystem 2 to 3 . Subscript $L$ means heat loss to surrounding, subscripts 1 and 2 refer to subsystems 1 and 2 .

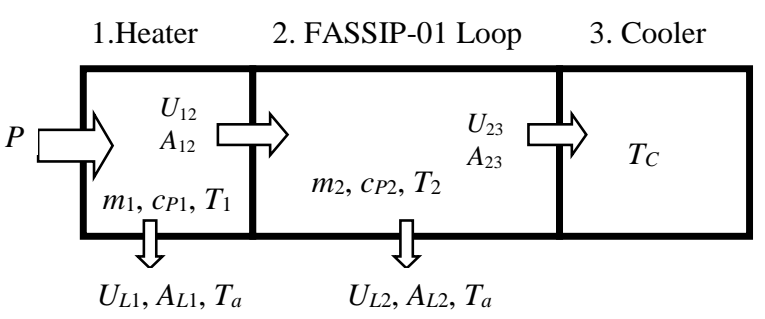

Fig. 2. Schematic model of heat transfer on the FASSIP-01 system.
By applying the law of energy balance, the equation of heat transfer in a transient state for the time interval $d t$ can be derived, starting from (12):

$$
\text { Energy reserved during } d t=(\text { Pin }- \text { Pout }) \times d t
$$

Applying the equation to subsystem 1:

$$
m_{1} c_{P 1} \frac{d T_{1}}{d t}=\left[P-\left\{U_{12} \cdot A_{12}\left(T_{1}-T_{2}\right)+U_{L 1} \cdot A_{L 1}\left(T_{1}-T_{a}\right)\right\}\right]
$$

And to sub-system 2:

$m_{2} C_{P 2} \frac{d T_{2}}{d t}=\left\{U_{12} \cdot A_{12}\left(T_{1}-T_{2}\right)-U_{L 2} \cdot A_{L 2}\left(T_{2}-T_{a}\right)-U_{23} \cdot A_{23}\left(T_{2}-T_{C}\right)\right\}$

Therefore,

$$
T_{1}=T_{2}+\left\{m_{2} c_{P 2} \frac{d T_{2}}{d t}+U_{L 2} A_{L 2}\left(T_{2}-T_{a}\right)+U_{23} \cdot A_{23}\left(T_{2}-T_{C}\right)\right\} /\left(U_{12} \cdot A_{12}\right)
$$

By substituting $T_{1}$ fom equation (15) to (13), a second-order differential equation in $T_{2}$ as a function of time is obtained. The equation is given in (16):

with

$$
K_{1} \frac{d^{2} T_{2}}{d t^{2}}+K_{2} \frac{d T_{2}}{d t}+K_{3} T_{2}=K_{4}
$$

$$
\begin{gathered}
K_{1}=m_{1} c_{P 1} \frac{m_{2} c_{p 2}}{U_{12} A_{12}} \\
K_{2}=m_{1} c_{P 1}\left(1+\frac{U_{L 2} A_{L 2}}{U_{12} A_{12}}+\frac{U_{23} A_{23}}{U_{12} A_{12}}\right)+m_{2} c_{p 2}\left(1+\frac{U_{L 1} A_{L 1}}{U_{12} A_{12}}\right) \\
K_{3}=U_{L 2} A_{L 2}+U_{23} A_{23}+U_{L 1} A_{L 1}\left(1+\frac{U_{L 2} A_{L 2}}{U_{12} A_{12}}+\frac{U_{23} A_{23}}{U_{12} A_{12}}\right) \\
K_{4}=P+\left(1+\frac{m_{1} c_{P 1}}{U_{12} A_{12}}+\frac{U_{L 1} A_{L 1}}{U_{12} A_{12}}\right)\left(U_{L 2} A_{L 2} T_{a}+U_{23} A_{23} T_{C}\right)
\end{gathered}
$$

Using numerical method explicitly with the time step of $\Delta t$, equation (16) can be solved to obtain the temperature $T_{2}$ as a function of time, resulting in (21):

$$
T_{2, t+\Delta t}=\frac{1}{C}\left[\left(\frac{2 K_{1}}{\Delta t^{2}}+\frac{K_{2}}{\Delta t}-K_{3}\right) T_{2, t}-\frac{K_{1}}{\Delta t^{2}} T_{2, t-\Delta t}+K_{4}\right]
$$

with $C=\frac{K_{1}}{\Delta t^{2}}+\frac{K_{2}}{\Delta t}$

In steady state, from (16), the steady-state temperature $T_{2 \text { steady }}$ can be calculated as

$$
T_{2 \_ \text {steady }}=\frac{K_{4}}{K_{3}}
$$

After obtaining $T_{2}$, either in transient or steady state, the temperature of $T_{l}$ can be calculated using (15).

In steady state, the temperature $T_{1_{-} \text {steady }}$ is given in (23).

$T_{1 \_ \text {steady }}=T_{2 \_ \text {steady }}+\left\{U_{L 2} A_{L 2}\left(T_{2}-T_{a}\right)+U_{23} \cdot A_{23}\left(T_{2}-\right.\right.$

$\left.\left.T_{C}\right)\right\} /\left(U_{12} \cdot A_{12}\right)$ 
The time response characteristics of $T_{2}$ depends of the determinant of the characteristic equation (15). The determinant value can be calculated as

$$
\text { Det }=K_{2}^{2}-4 K_{1} K_{3}
$$

The more positive the determinant is, the more damped the temperature transient response is. Inversely, the more negative the determinant is, the more oscillatory the response is.

\section{MODELING AND SIMULATION}

The MATLAB-based program for steadystate and transient conditions follows the flow chart in Fig. 3. The first step defines the loop geometry and FASSIP-01 initial physical properties, and the second step sets the initial flow rate and temperature. These initial parameters were used as reference in the determination of dimensionless numbers required to compute the heat transfer coefficient, flow rate, and heat loss. The computation was performed iteratively by considering the changes of physical properties of the fluid and the air with temperature that were determined at each iteration.

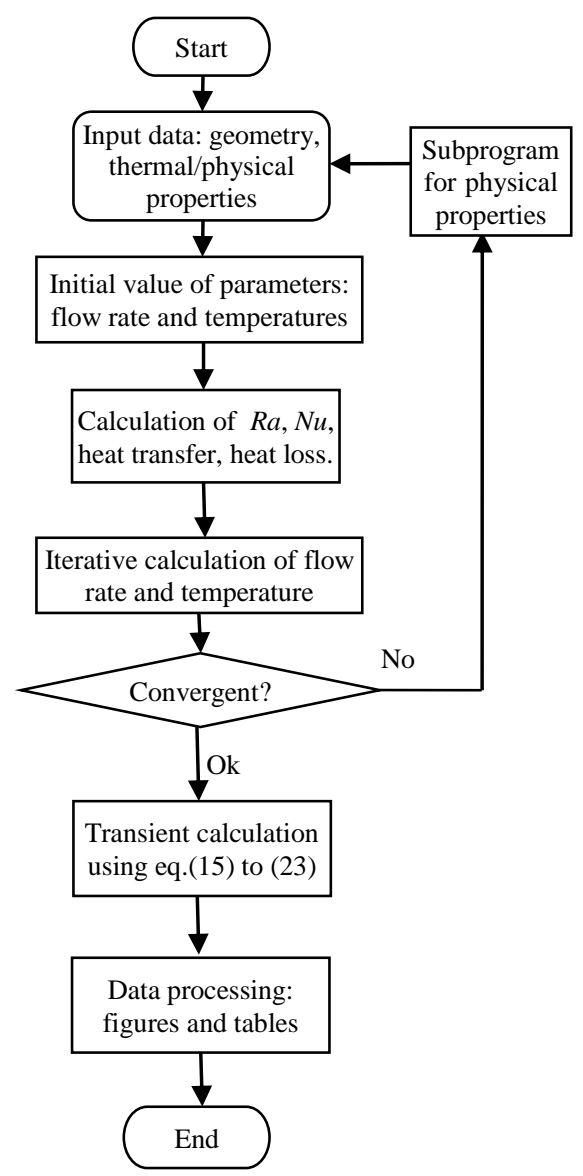

Fig. 3. Flow diagram of MATLAB programming for steady and transient conditions.
After the parameter values converged or changed relatively little in the iteration, the data was processed to show the relationship between the required parameters in this study, such as:

1. Effect of h-cooler on the temperature distribution on the loop FASSIP-01.

2. Effect of h-cooler and heater power on the hottest and coldest temperatures of the water in the loop.

3. Effect of h-cooler and heater power on the flow rate on the loop FASSIP-01.

4. Effect of $\Delta Z$ and h-cooler on the loop water flow rate.

5. Effect of the loop insulation thickness on flow rate, heat loss, and water temperature.

MATLAB-based programming was also carried out to determine the temperature transient toward a steady state by using equations (15) to (23) in order to estimate the time required to reach steady state. The schematic models used in the transient calculation is already presented in the Fig. 2, with three subsystems separated from each other. The water inside the heater tank was considered as the first subsystem, while the second subsystem was the water inside the rectangular loop, and the third subsystem was the water inside the cooler tank. The temperature of the third subsystem is assumed to be constant in this analysis. By this model, the transient of loop temperature can be calculated using (21), and the transient of heater water temperature can be calculated using (15). In steady state, the loop water temperature is determined by (22), and heater water temperature by (23). In applying these equations to FASSIP-01 system, the parameters used were defined as follows: $m_{1}$ was the mass of heater tank water $(\mathrm{kg}), m_{2}$ was the mass of loop water $(\mathrm{kg}), T_{1}$ was the heater water temperature $\left({ }^{\circ} \mathrm{C}\right), T_{2}$ was the rectangular loop water temperature $\left({ }^{\circ} \mathrm{C}\right), T_{a}$ was the ambient temperature $\left({ }^{\circ} \mathrm{C}\right), T_{c}$ was the temperature of cooler secondary side $\left({ }^{\circ} \mathrm{C}\right), U_{12}$ was the global heat transfer coeficient between heater water and loop water $\left(\mathrm{W} \mathrm{m}^{-2}{ }^{\circ} \mathrm{C}^{-1}\right)$, $A_{12}$ was the heat transfer surface area between heater water and loop water $\left(\mathrm{m}^{2}\right), U_{23}$ was the total heat transfer coeficient between loop water and cooler water $\left(\mathrm{W} \mathrm{m}^{-2}{ }^{\circ} \mathrm{C}^{-1}\right), A_{23}$ was the heat transfer surface area between loop water and cooler water $\left(\mathrm{m}^{2}\right), U_{L 1}$ was the total heat transfer coeficient between heater tank water and environment $\left(\mathrm{W} \mathrm{m}^{-2}{ }^{\circ} \mathrm{C}^{-1}\right), A_{L 1}$ was the heat transfer surface area between heater tank water and environment $\left(\mathrm{m}^{2}\right), U_{L 2}$ was the total heat transfer coeficient between loop water and environment ( $\mathrm{W} \mathrm{m}^{-2}{ }^{\circ} \mathrm{C}^{-1}$ ), and $A_{L 2}$ was the heat transfer surface area between loop water and environment $\left(\mathrm{m}^{2}\right)$. 


\section{RESULTS AND DISCUSSION}

The main result of this research is the completion of MATLAB-based calculation program that is able to simulate the influence of several parameters to other important parameters in FASSIP-01 loop, either in steady-state or transient condition. Figure 4 shows the effect of h-cooler on the water temperature distribution in the loop for the heat power entering the rectangular loop of $1000 \mathrm{~W}$.

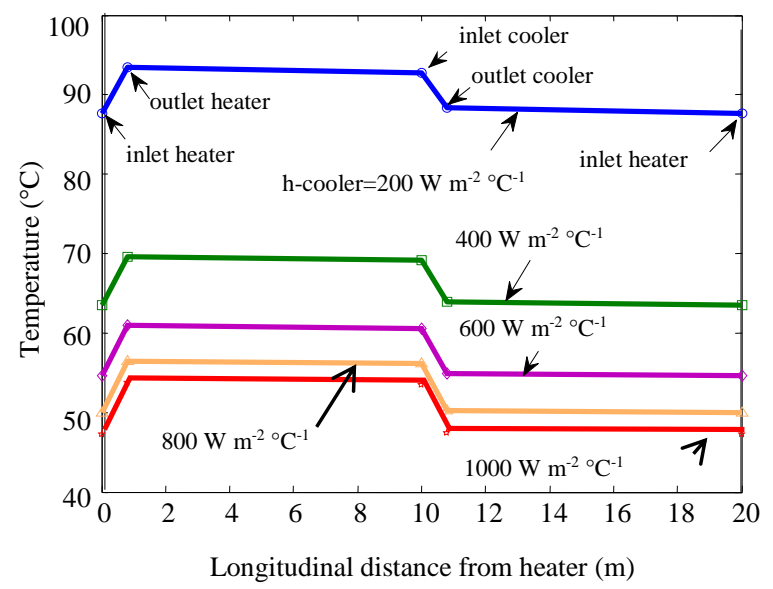

Fig. 4. Effect of h-cooler on temperature distribution of FASSIP-01.

It appears that the effect of the cooling ability (represented by h-cooler) to the water temperature in the loop was very significant. If h-cooler was less than $200 \mathrm{~W} \mathrm{~m}^{-2}{ }^{\circ} \mathrm{C}^{-1}$, the loop water temperature had a great possibility to boil because the temperature was close to the boiling point of $100{ }^{\circ} \mathrm{C}$. Figure 5 shows how the hottest and coldest temperatures in the loop were significantly affected by h-cooler and heater power. The influence of h-cooler on the temperature was less significant at higher values. The critical value of h-cooler where the water was starting to boil depended on heating power. Increasing the heating power also increased the critical value of h-cooler.

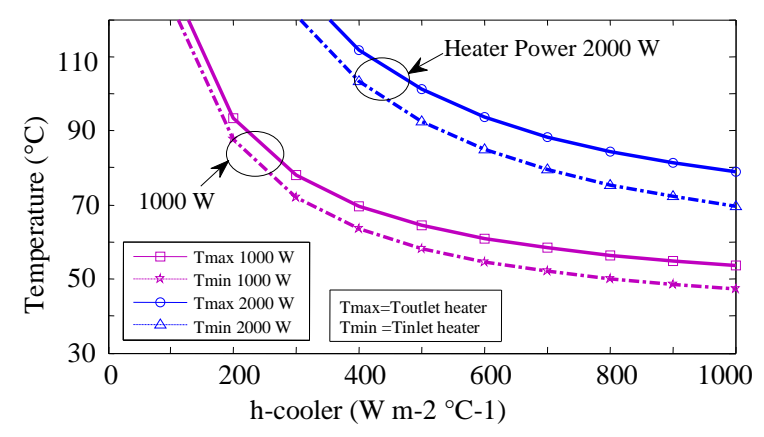

Fig. 5. Hottest and coldest loop water temperature.

As seen in the figure, in order to avoid boiling in the loop, the value of h-cooler should not be less than
$200 \mathrm{~W} \mathrm{~m}^{-2}{ }^{\circ} \mathrm{C}^{-1}$ for the heating power of $1000 \mathrm{~W}$ and a minimum of $500 \mathrm{~W} \mathrm{~m}^{-2}{ }^{\circ} \mathrm{C}^{-1}$ for the heating power of $2000 \mathrm{~W}$. In practice, cooling ability can be increased by expanding the contact area of the cooler and/or by increasing the fluid velocity in secondary side.

The result of calculation of water flow rate in FASSIP-01 loops using (4) and (6) for two different heating powers is shown in Fig. 6.

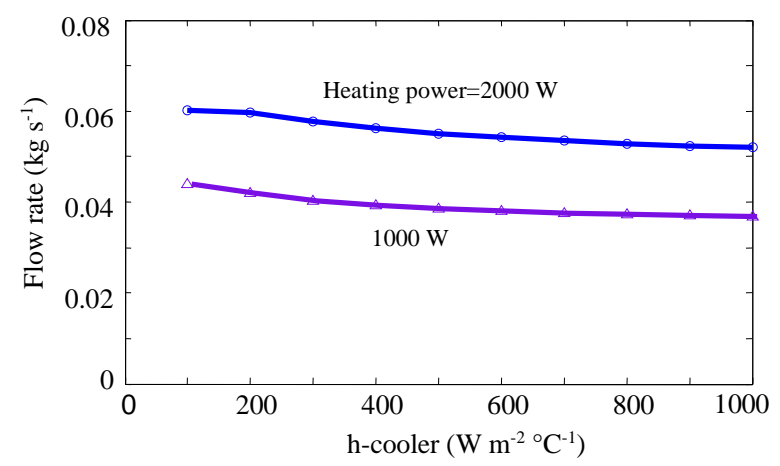

Fig. 6. The flow rate of water in the FASSIP-01 loop.

It is shown that with the increase of h-cooler there was a slight decrease in flow rate. That is because the increase in $\mathrm{h}$-cooler caused the water temperature to decrease, significantly decreasing its coefficient of thermal expansion, as seen in Table 1, thus idecreasing the buoyancy force. The value of flow rate and its relation with the heater power are in good agreement with references [12] and [14].

The influence of $\Delta Z$ is shown in Fig. 7. It can be seen that the greater the elevation difference, the greater the flow rate generated. This is due to the increase of the lifting capacity of the water with increasing the elevation difference. According to equation (6), the water flow rate is proportional to the elevation difference $\Delta Z$ and the cube root of the coeficient of thermal expasion.

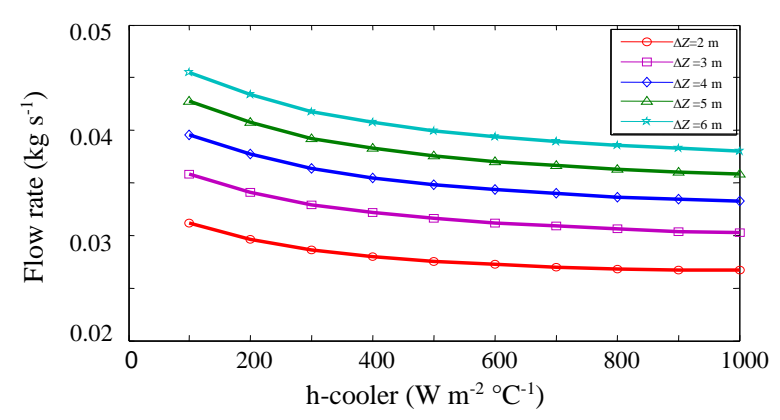

Fig. 7. Effect of elevation difference on flow rate.

The influence of insulation thickness of rectangular loop pipe on the thermal parameters of FASSIP-01 in steady condition with $2000 \mathrm{~W}$ of heating power, $1000 \mathrm{~W} \mathrm{~m}^{-2}{ }^{\circ} \mathrm{C}^{-1}$ of h-cooler and no insulation of heater tank is shown in Table 2 . 
The insulation thickness (IT) was varied from 0 to $50 \mathrm{~mm}$ using glasswool material with a termal conductivity of $0.038 \mathrm{~W} \mathrm{~m}^{-1}{ }^{\circ} \mathrm{C}^{-1}$. The thermal parameters to be evaluated in steady state were loop heat loss $Q_{l}$, heater heat loss $Q_{l h}$, loop water temperature $T_{1}$, heater tank water temperature $T_{\mathrm{h}}$, velocity $V$, and mass flow rate $\dot{m}$ of water flow in the rectangular loop.

With increasing loop insulation thickness, it is reasonable that the loop heat loss decreased because of the decreasing total heat transfer coeficient between the loop water and the surrounding air even though the loop water temperature increased.

Table 2. Effect of loop insulation thickness on thermal parameters with no heater insulation

\begin{tabular}{ccccccc}
\hline $\begin{array}{c}\mathrm{IT} \\
(\mathrm{mm})\end{array}$ & $\begin{array}{c}Q_{l} \\
(\mathrm{~W})\end{array}$ & $\begin{array}{c}Q_{l h} \\
(\mathrm{~W})\end{array}$ & $\begin{array}{c}T_{l} \\
\left({ }^{\circ} \mathrm{C}\right)\end{array}$ & $\begin{array}{c}T_{h} \\
\left({ }^{\circ} \mathrm{C}\right)\end{array}$ & $\begin{array}{c}V \\
\left(\mathrm{~m} \mathrm{~s}^{-1}\right)\end{array}$ & $\begin{array}{c}\dot{m} \\
\left(\mathrm{~kg} \mathrm{~s}^{-1}\right)\end{array}$ \\
\hline 0 & 279.4 & 720.6 & 46.8 & 97.7 & 0.0779 & 0.0339 \\
10 & 139.6 & 697.0 & 51.3 & 100.3 & 0.0814 & 0.0353 \\
20 & 107.6 & 672.0 & 53.0 & 102.3 & 0.0831 & 0.0360 \\
30 & 92.5 & 652.2 & 54.1 & 103.8 & 0.0844 & 0.0365 \\
40 & 83.4 & 636.2 & 54.9 & 105.0 & 0.0853 & 0.0369 \\
50 & 77.3 & 623.0 & 55.5 & 106.0 & 0.0861 & 0.0372 \\
\hline
\end{tabular}

Following the increase of the loop temperature, the heater temperature increased. It may appear that an increase of heater heat loss would ensue, but it was not so as the heat transfer coefficient decreased more significantly with temperature than the increase of the temperature itself. The result of $0 \mathrm{~mm}$ loop insulation thickness or uninsulated condition shows that the largest heat loss passed through the heater tank. In this condition, the heat power transferred to the rectangular loop was $1279.4 \mathrm{~W}$ from the $2000 \mathrm{~W}$ heating power. From this heat power, $279.4 \mathrm{~W}$ was lost through the rectangular loop wall, leaving $1000 \mathrm{~W}$ heat power to be evacuated by the cooler. If it is intended to transfer the maximum heat power from the heater to the cooler, this condition is undesirable, and insulation is needed either for loop pipe or heater tank. However, if the purpose is to simply evacuate heat from the heater, the insulation is not needed. The disadvantage of using the insulation is the increase of water temperature both in heater tank and in the rectangular loop. If the heater tank is not pressurized or under atmospheric pressure, the boiling temperature is $100^{\circ} \mathrm{C}$. In Table 2 , it is shown that the heater water boiled for $10 \mathrm{~mm}$ or more of loop insulation thickness. If it is not avoided, the water volume in the heater tank will continue decreasing.

In the condition where the heater tank was also given $50 \mathrm{~mm}$-thick insulation, the result is shown in Table 3. Comparing to the result presented in Table 2, it is clear that the temperatures in both subsystems were higher. The loop heat loss decreased with increasing the thickness of insulation. The heat power evacuated by the cooler increased, inducing the increase of the flow rate.

Table 3. Effect of loop insulation thickness on thermal parameters with $50 \mathrm{~mm}$ heater insulation

\begin{tabular}{ccccccc}
\hline $\begin{array}{c}\mathrm{IT} \\
(\mathrm{mm})\end{array}$ & $\begin{array}{c}Q_{l} \\
(\mathrm{~W})\end{array}$ & $\begin{array}{c}Q_{l h} \\
(\mathrm{~W})\end{array}$ & $\begin{array}{c}T_{l} \\
\left({ }^{\circ} \mathrm{C}\right)\end{array}$ & $\begin{array}{c}T_{h} \\
\left({ }^{\circ} \mathrm{C}\right)\end{array}$ & $\begin{array}{c}V \\
\left(\mathrm{~m} \mathrm{~s}^{-1}\right)\end{array}$ & $\begin{array}{c}\dot{m} \\
\left(\mathrm{~kg} \mathrm{~s}^{-1}\right)\end{array}$ \\
\hline 0 & 518.8 & 89.7 & 61.2 & 137.2 & 0.1048 & 0.0452 \\
10 & 253.7 & 91.9 & 68.8 & 140.5 & 0.1089 & 0.0468 \\
20 & 189.6 & 92.2 & 70.6 & 141.4 & 0.1099 & 0.0472 \\
30 & 159.0 & 92.2 & 71.5 & 141.8 & 0.1103 & 0.0474 \\
40 & 140.7 & 92.1 & 72.0 & 142.1 & 0.1106 & 0.0475 \\
50 & 128.2 & 91.9 & 72.3 & 142.3 & 0.1108 & 0.0475 \\
\hline
\end{tabular}

Figure 8 shows the increasing temperature of water in loop and heater as a function of time for loop insulation thicknesses varying from 0 to $50 \mathrm{~mm}$.

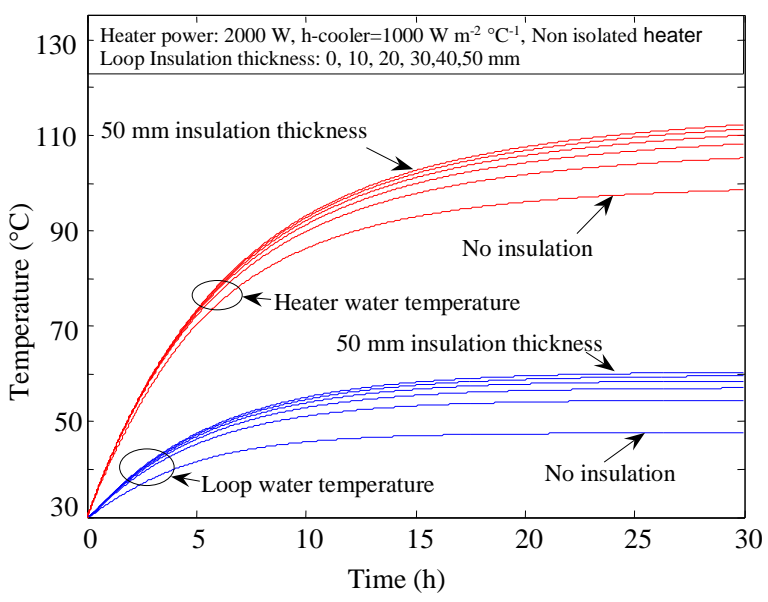

Fig. 8. Transient of loop water temperature and heater water temperature.

Remark can be made in viewing this result that the time needed to reach the steady state is very long (more than $20 \mathrm{~h}$ ). The response time is comparable to that calculated by Ekariansyah et al. [17] using RELAP5/SCDAP/Mod3.4 for the FASSIP-01 loop that needed more than $20 \mathrm{~h}(72000 \mathrm{~s})$ to reach the steady state, as shown in Fig. 9.

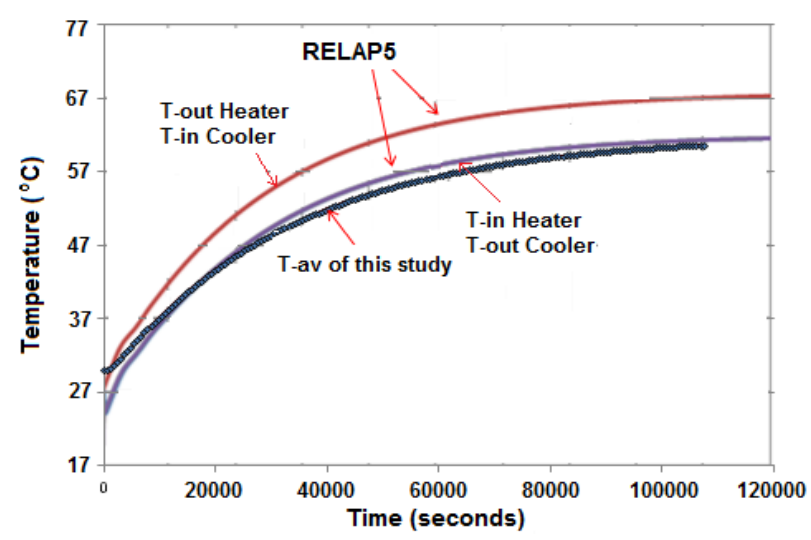

Fig. 9. Comparison of temperature transient against RELAP5 result [17]. 
This is incovenient for the implementation of experiments where time is limited to within the working hours, so a special effort is required to reduce the time towards steady state. Most probably, the long time response is due to the big volume of heater tank. Effects of the heater tank volume to average temperature change for the power of $1000 \mathrm{~W}$ and $\mathrm{h}$-cooler of $500 \mathrm{~W} \mathrm{~m}{ }^{-2}{ }^{\circ} \mathrm{C}^{-1}$ are presented in Fig. 10. Seen in the figure, the change of average temperature with times follows an exponential function as shown in equation (25).

$$
T_{t}-T_{0}=\left(T_{s}-T_{0}\right)\left(1-e^{-\frac{t}{\tau}}\right)
$$

In (25), $T_{t}$ is the average temperature $\left({ }^{\circ} \mathrm{C}\right)$ at time $t$ (h), $T_{0}$ is the initial temperature $\left({ }^{\circ} \mathrm{C}\right), T_{s}$ is the steady state temperature $\left({ }^{\circ} \mathrm{C}\right)$, and $\tau$ is the time constant (h) that can be determined from each curve depending on each heater tank's volume $\left(\mathrm{m}^{3}\right)$. The corresponding correlation between the time constant $\tau$ and the heater volume $V h$ is strongly linear as shown in equation 26.

$$
\tau=55 V h+0.383
$$

with determination coefficient of linear regression $R^{2}=0.999$. Reducing the heater tank volume from $0.1 \mathrm{~m}^{3}$ to $0.03 \mathrm{~m}^{3}$ reduced the time constant from 5.883 hours to 2.033 hours. With these time constants, the times needed to reach $95 \%$ towards steady state are $13.5 \mathrm{~h}$ and $4.7 \mathrm{~h}$, respectively.

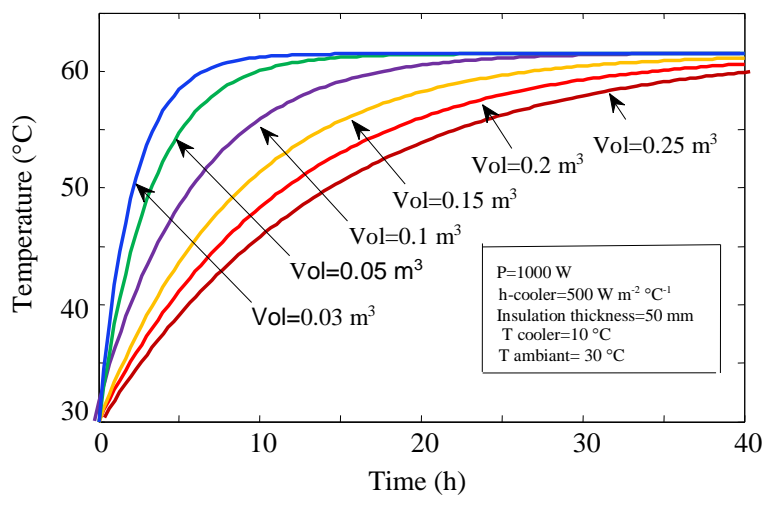

Fig. 10. Effect of heater tank volume to temperature change of loop water.

Another way to reduce the response time in reaching the steady state was by varying the heater input power, starting from a higher power in the beginning and reducing step by step to steady state power. Figure 11 shows that with a starting power of $150 \%$ of steady-state power for two hours, followed by reducing to $125 \%$ of steady-state power for two hours, and continuing with steady state power, the steady state was reached more rapidly, requiring approximately only five hours. Although in the beginning the heater power was relatively high, with just two hours of application, the temperature of heater water was maintained lower than the saturation temperature.

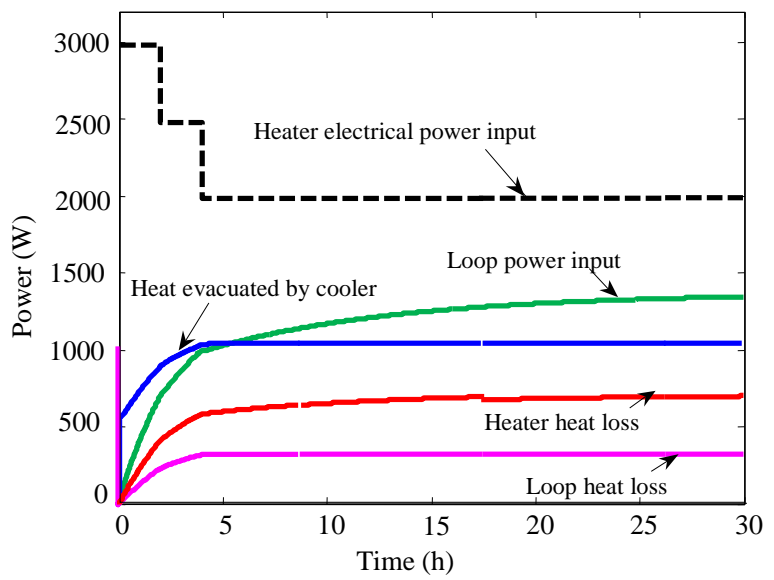

Fig. 11. Power transient distribution in FASSIP-01 with modified heater input power.

\section{CONCLUSION}

This research has produced a software package that is able to predict the thermal characteristics of the FASSIP-01 loop in steady or transient conditions. Predictions have shown that for transferring the heater power of $1000 \mathrm{~W}$ and $2000 \mathrm{~W}$ without boiling condition, an h-cooler of more than 200 and $400 \mathrm{~W} \mathrm{~m}^{-2}{ }^{\circ} \mathrm{C}^{-1}$, respectively, was needed. For a h-cooler of $200 \mathrm{~W} \mathrm{~m}{ }^{-2}{ }^{\circ} \mathrm{C}^{-1}$, the circulation flow rate increased from 0.04 to $0.06 \mathrm{~kg} / \mathrm{s}$ as the heater power increased from $1000 \mathrm{~W}$ to $2000 \mathrm{~W}$. Those flow rates decreased to 0.037 and $0.052 \mathrm{~kg} / \mathrm{s}$ when h-cooler was increased to $1000 \mathrm{~W} \mathrm{~m}^{-2}{ }^{\circ} \mathrm{C}^{-1}$. The flow rates predicted are in agreement with other studies on rectangular loops in the literature. Increasing the insulation thickness in heater tank or in the loop will increase the capability of the loop to transfer the heat from the heat source to the heat sink. The time needed to reach $95 \%$ towards steady state was predicted to be more than 13 hours. Reduction of this time to less then five hours was possible by reducing the heater tank volume from $100 \mathrm{~L}$ to $30 \mathrm{~L}$ or by modifying the starting heater input power.

\section{ACKNOWLEDGMENT}

The author is grateful to the Center for Nuclear Reactor Technology and Safety for providing financial support in performing the work on FASSIP-01 thermosyphon loop through the DIPA of 2015. The author also thank to 
Dr. Mulya Juarsa for providing all informations needed concerning the FASSIP-01 design data.

\section{REFERENCES}

1. P. Trinuruk and T. Obara, Ann. Nucl. Energy 63 (2014) 437.

2. J.I.N.H.O. Song and T.A.E.W. Kim, Nucl. Eng. Technol. 46 (2014) 207.

3. R. Abdollah and T. Hessam, Therm. Sci. 15 (2011) 447.

4. G. Strydom and H.D. Gougar, Nucl. Eng. Des. 256 (2013) 304.

5. D. Irwanto and T. Obara, Ann. Nucl. Energy 60 (2013) 383.

6. C. Ye, M. Zheng, Y. Wang et al., Nucl. Sci. Tech. 24 (2013) 1.

7. Y.P. Zhang, S.Z. Qiu, G.H. Su et al., Nucl. Eng. Des. 242 (2012) 247.
8. L.J. Lommers, B.E. Mays and F. Shahrokhi, Nucl. Eng. Des. 271 (2014) 569.

9. Z. Sui, J. Sun, C. Wei et al., Nucl. Eng. Des. 271 (2014) 479.

10. Y. Chung, S. Lim and K. Bae, Sci. Technol. Nucl. Install. 2014 (2014) 1.

11. O. Sambuu and T. Obara, Prog. Nucl. Energy (2014) 1.

12. M. Krishnani and D.N. Basu, Int. J. Therm. Sci. 105 (2016) 224.

13. K. Naveen, K.N. Iyer, J.B. Doshi et al., Prog. Nucl. Energy 76 (2014) 148.

14. K. Naveen, K.N. Iyer, J.B. Doshi et al., Prog. Nucl. Energy 75 (2014) 105.

15. H. Tjahjono, Tri Dasa Mega 17 (2015) 159.

16. H. Tjahjono, Tri Dasa Mega 17 (2015) 1. (in Indonesian)

17. A.S. Ekariansyah, H. Tjahjono, M. Juarsa et al., Sigma Epsil. 19 (2015) 32. 